\title{
Hvorfor kulturpolitik?
}

\author{
Trine Bille
}

I artiklen "Why Urban Cultural Policies?" (SkotHansen, 2005) præsenterer Dorte en model, der kan benyttes som udgangspunkt for analyse af rationaler eller legitimering af kulturpolitik. Modellen er udarbejdet som en del af EU-projektet EUROCULT21 og er tænkt i forhold til kulturpolitik i europæiske byer, men den kan ligeså vel anvendes i forhold til national kulturpolitik.

Modellen er bygget op om de fire E'er: Empowerment, Enlightenment, Economic Impact og Entertainment (se figur 1). Modellen bringer orden i kaos ved at danne grundlag for en struktureret debat om de mange og til dels modsatrettede kulturpolitiske målsætninger, og den har vist sig meget anvendelig i praksis. Som Dorte viser i artiklen, kan forskellige typer af kulturaktiviteter begrundes i ét eller flere af de fire E'er.

Modellen har også vist sig at spille godt sammen med et samfundsøkonomisk blik på offentlig kulturpolitik, og netop den sammenhæng vil jeg uddybe i denne artikel.

\section{Samfundsøkonomisk teori og værdi}

Der findes to afgørende forskellige perspektiver i samfundsøkonomisk teori: Det velfærdsøkonomiske

Trine Bille, associate professor, cand.polit., ph.d. Copenhagen Business School, Institut for Ledelse PolitikogFilosofi,tbi.mpp@cbs.dk

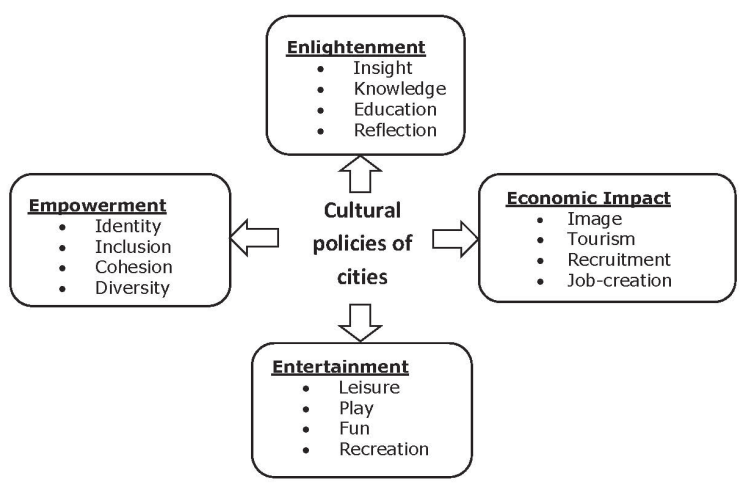

Figur 1. De fire rationaler i urban kulturpolitik. (Skot-Hansen, 2005).

perspektiv og det markedsøkonomiske perspektiv. Hvor den velfærdsøkonomiske tankegang handler om at maksimere samfundets nytte og fordele "kagen" bedst muligt, handler det markedsøkonomiske perspektiv om økonomisk vækst og om at gøre den samlede "kage" større. Det markedsøkonomiske perspektiv tager udgangspunkt i den værdi, som kan handles på markedet og kan opgøres på BNP. Den velfærdsøkonomiske værdi tager derimod udgangspunkt i den enkelte borgers subjektive opfattelse af livskvalitet og værdi. Det anerkendes, at der eksisterer væsentlige værdier, som ikke handles på markedet (non-market værdier), men som alligevel repræsenterer en væsentlig værdi for borgerne, og derfor må tages med $\mathrm{i}$ betragtning, når de offentlige ressourcer skal fordeles og den samfundsøkonomiske værdi skal vurderes (Bille, 2012). 


\section{Økonomisk vækst}

Kulturens betydning for økonomisk vækst relaterer det sig til de to E'er "Economic Impact" og "Entertainment" i Dortes model.

Som Dorte skriver, handler Economic Impact om image, turisme og jobskabelse, og det vil bl.a. være aktiviteter som store event og festivaller eller flagskibsprojekter, som et nyt kulturhus, der vil skabe economic impact og dermed økonomiske vækst.

Kulturens betydning for economic impact, er et argument, der ofte har været brugt i den offentlige debat, men det rejser nogle problemer, hvis det bliver brugt som rationale, dvs som argument for offentlige kulturstøtte. Problemet er, at selvom nogle kulturaktiviteter kan have økonomisk impact i form af $\mathrm{fx}$ jobskabelse, så er det ikke et argument i sig selv, for al økonomisk aktivitet har økonomisk impact i varierende grad. Hvis det skal bruges som argument for offentlig kulturstøtte må effekterne sammenlignes med effekterne af alternative anvendelser af pengene. Derfor må formålet med kulturaktiviteterne tages med i betragtning. Formålet med kulturaktiviteter er sjældent at skabe økonomisk impact i form af øget omsætning og beskæftigelse. Det kan være sidegevinster, men ikke det egentlige formål. Formålet med fx et bibliotek er ikke at skabe omsætning og beskæftigelse i lokalområdet. Hvis det var formålet ville det uden tvivl være bedre, at det offentlige støttede noget andet end biblioteket. Det siger næsten sig selv, at bibliotekets formål ikke er at skaffe job til bibliotekarer, og at bibliotekets værdi ikke kan måles på hvor mange bibliotekarer der er ansat, og hvor stort et privatforbrug disse bibliotekarer har.

Hvis argumentet om economic impact skulle bruges til legitimering af kulturpolitik, så betyder det i sin yderste konsekvens, at samfundet skal støtte den kultur der skaber størst økonomisk aktivitet. Fx store events med stjernekunstnere, som tiltrækker mange turister, der bruger penge i lokalområdet. Men når formålet med den offentlige kulturpolitik er noget andet - samtidig med at økonomisk vækst uden tvivl skabes bedre og mere effektivt ved andre erhvervspolitiske tiltag - så kan en fokus på kulturens kortsigtede økonomiske impact skabe en forfejlet kulturpolitik.
Entertainment kan, som Dorte skriver, ikke ses som et egentligt mål for offentlig kulturpolitik. Men alle kulturaktiviteter har et væsentligt element af underholdning i sig. For de kreative industrier og den kommercielle kultur, er dette mål nok mere fremherskende end for den offentligt støttede kultur. Netop de kommercielle kreative industrier er særligt knyttet til perspektivet om økonomisk vækst, da de kreative industrier kan skabe betydelige markedsværdier i form af øget beskæftigelse, omsætning og eksport. Imidlertid støtter det offentlige generelt ikke kommercielle virksomheder i vækst, men den offentlige politik kan skabe gode rammebetingelser for de kreative industriers udvikling, fx ved zoning, inspiration og viden (Mathiasen et al., 2006; CKO, 2011; Bille og De Paoli, 2012).

\section{Velfærd}

Det andet perspektiv er velfærd. Basal samfundsøkonomi tager udgangspunkt $i$, at det er samfundets samlede velfærd, der skal maksimeres. Og samfundet består af borgerne. Samfundet skal derfor producere de varer og serviceydelser, som maksimerer borgernes nytte, herunder den kunst og kultur som efterspørges. Det meste klares af markedsmekanismerne, som på de fleste områder er velegnet til at regulere udbud og efterspørgsel. Det gælder dog ikke for alle varer og serviceydelser, at markedet er godt til at regulere udbuddet. Dette gælder fx ikke for offentlige goder. For offentlige goder som $\mathrm{fx}$ det nationale forsvar, gadebelysning etc. kan markedet ikke regulere udbud og efterspørgsel, idet det er umuligt og uhensigtsmæssigt at udelukke nogle borgere fra at benytte disse services, og derfor umuligt at indføre direkte brugerbetaling. Uden brugerbetaling er der ingen private udbydere, der har lyst til at udbyde ydelserne, fordi alle har glæde af dem, hvad enten de betaler for dem eller ej. Meget kulturudbud er ikke "rene offentlige goder" i den økonomisk-teoretiske betydning, men derimod private goder med eksterne effekter. Private goder fordi den enkelte kulturforbruger har glæde af at læse en bog, se et teaterstykke, se en film, besøge et museum, og derfor er villige til at betale for denne oplevelse. Men meget kultur har bredere samfundsøkonomiske effekter fordi hele samfundet har gavn af kulturaktiviteterne - det gælder også ikke-brugerne. Disse eksterne effekter kan være viden, indsigt, dannelse, refleksion, myndiggørelse, identitet, fællesskab og sundhedseffekter som ikke alene kommer den enkelte kulturforbruger, men hele samfundet til 
gode. Mange undersøgelser viser, at borgerne faktisk er villige til at betale for disse værdier over deres skat - også for kulturaktiviteter, som de aldrig selv bruger (se fx Bille Hansen, 1997, for et eksempel med Det Kgl. Teater). Og dette er det væsentligste argument for offentlige tilskud til kultursektoren.

Her kan der igen relateres til de 4 rationaler, idet de eksterne effekter, som danner udgangspunkt for det velfærdsøkonomiske argument, knytter sig tæt til de 2 andre E'er i modellen, nemlig Enlightenment og Empowerment. Enlightenment er fx den indsigt, viden, uddannelse og refleksion, som forskellige kulturaktiviteter kan skabe, og som særligt er rationalet bag kulturaktiviteter som bevarelse af kulturarven, demokratisering af kulturen og publikumsudvikling, kunstuddannelser og støtte til produktionen af nyt kunst. Empowerment knytter sig bl.a. til kultures betydning for identitet, inklusion, sammenhængskraft og diversitet, og her bliver kulturaktiviteter som lokal kunst, social og etnisk kultur, subkulturer og lokale medier af stor betydning. Støttes disse aktiviteter vil det i mange tilfælde ikke alene kommer deltagerne til gode, men også ikke-brugerne og dermed samfundet som helhed.

Fra et velfærdsøkonomisk perspektiv bør det offentlige altså tage udgangspunkt $\mathrm{i}$ kulturens betydning for borgerens Enlightenment og Empowerment, og støtte de kulturaktiviteter, der har den største velfærdsøkonomiske non-market værdi, fx i form af oplysning og social udvikling. I praksis er det selvfølgelig en vanskelig opgave at håndtere, idet disse non-market værdier er karakteriseret ved, at de er vanskelige at måle. Men som princip for den offentlige tilskudsfordeling er det en betydningsfuld ledetråd.

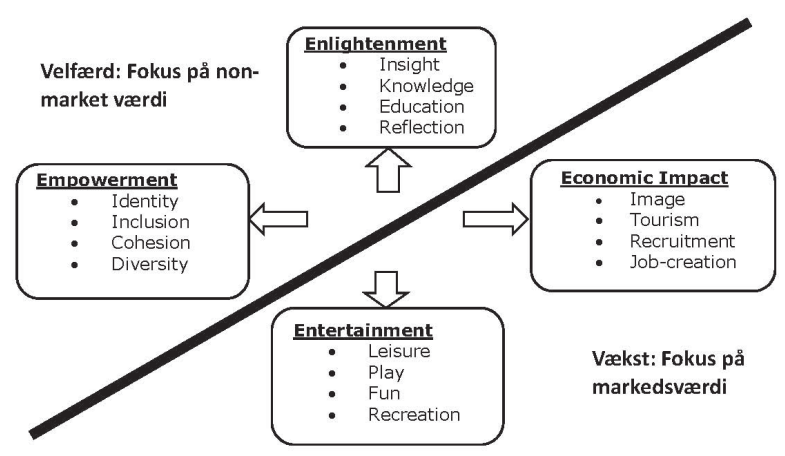

Figur 2. De fire rationaler i relation til vaekst og velfoerd. Kilde: Egen tilvirkning med udgangspunkt $i$ Skot-Hansen, 2005.

\section{Urban versus national kulturpolitik}

Modellen med de fire E'er er lavet med udgangspunkt $i$ et urbant eller lokalt perspektiv. Jeg mener imidlertid at den i ligeså høj grad er anvendelig i forhold til national kulturpolitik.

Set det ud fra et urbant eller lokalt perspektiv vil Economic Impact typisk have større vægt end på nationalt niveau. Det skyldes, at på nationalt niveau vil mange af de markedsøkonomiske effekter være et nul-sums-spil forstået på den måde, at væksten der sker i ét lokalområde, sker på bekostning af vækst $i$ et andet lokalområde. Tiltrækkes besøgende til en bestemt by på grund af $\mathrm{fx}$ en megakoncert, vil de bruge penge i denne by i stedet for i deres hjemby. Det samme gælder når kulturtilbud tiltrækker nye indbyggere eller virksomheder. Med mindre der er tale om udenlandske indbyggere eller virksomheder, så vil væksten det ene sted ske på bekostning af væksten et andet sted. Fra et nationalt perspektiv kan det forekomme uhensigtsmæssigt at byer eller regioner på denne måde konkurrerer om besøgende, indbyggere og virksomheder. For den enkelte by eller kommune giver det imidlertid god mening, idet det kan være nødvendigt at "følge med" og investere på samme niveau som (eller mere end) andre byer eller kommuner, for at følge med i udviklingen og ikke sakke agterud. Det samme gælder konkurrencen mellem byer eller regioner med hensyn til at tiltrække de "hippe" kreative industrier.

Derimod gælder det ikke de velfærdsøkonomiske værdier. Her er der ikke tale om konkurrence og nul-sumspil, men om at de samlede værdier vil blive større, hvis der også investeres lokalt i kulturinstitutioner og aktiviteter, der bidrager med kulturel værdi og til oplysning og social udvikling.

\section{Instrumentalisering versus kulturens egenværdi}

Dorte diskuterer afslutningsvis i artiklen spørgsmålet om instrumentalisering, dvs i hvilken grad kultur bruges som instrument til at opnå andre samfundsøkonomiske målsætninger, fx økonomiske eller sociale. I det meste af den kulturpolitiske forskningslitteratur ses denne instrumentalisering som et onde (fx Duelund, 2003 og Belfiore, 2003). Dorte citerer Vestheim (1994), der definerer instrumentel kulturpolitik således: "To use cultural venues and cultural as means or investments to attain goals in other than 
cultural areas...the instrumental aspect lies in emphasizing culture and cultural ventures as a means and not an end in itself" (Skot-Hansen, 1995, p.31).

Begrebet "instrumentel kulturpolitik" kan imidlertid kritiseres, hvilket Dorte også gør. For alle de 4 rationaler, som modellen præsenterer er instrumentelle: "Basically, all four rationales presented here are instrumental - i.e. they serve as means rather than goals in themselves - including the Enlightenment rationale with its emphasis on education as the route towards the enlightened democracy" (Skot-Hansen, 2005 p. 37). Dorte introducerer derfor et femte E: Experience. Det er baseret på Joli Jensens (2003) artikel, som netop fremhæver, at alle rationaler er instrumentelle, fordi de fokuserer på hvad kunst og kultur $g ø r$, i stedet for at fokusere på, hvad det er. Med det femte rationale Experience, mener Dorte således at "we must start learning more about how and why people like what they like and choose what they choose", og med det femte rationale "the main objective will be whether these activities fulfil the need for meaningful aesthetic experience for all groups and lifestyles of city, not only the privileged". (SkotHansen, 2005, p. 38).

Jeg mener imidlertid, at man også kan argumentere for stort set den samme konklusion på en anden måde. De fire rationaler er alle instrumentelle. Det er der ikke noget galt med. Men der er afgørende forskel på de rationaler, der knytter sig til det markedsøkonomiske perspektiv om økonomisk vækst, og de rationaler der knytter sig til det velfærdsøkonomiske perspektiv.

De fleste kan nok blive enige om, at kunstens og kulturens grundlæggende værdi findes i dens betydning for os mennesker, for vores selvforståelse, væremåde, holdninger, kreativitet, livskvalitet, æstetiske sans, sociale kritik mv. Det er derfor kunsten er så vigtig. Også for samfundet som helhed. Stimuleres menneskers kreativitet kan det have betydning for samfundets innovationsniveau. Forstærkes menneskers selvforståelse og forståelse for andre mennesker, kan det også have stor betydning på samfundsniveau, fx forståelse for demokrati, diversitet og meget mere. Kulturen er meningsbærende og har dermed en meget vigtig funktion. Dette relaterer sig alt sammen til rationalerne Enlightenment og Empowerment, og er dermed også instrumentelt i den forstand, at kulturen har betydning for den enkelte borger og på samfundsniveau. Men hvor rationalerne Enlighthenment og Empowerment er tæt knyttet til den grundlæggende betydning af kunst og kultur for os mennesker og dermed "kulturens egenværdi", er de markedsøkonomiske rationaler knyttet til andre samfundsmæssige mål som økonomisk vækst. Rationalet "Economic Impact" handler om, at kultur bruges som et instrument der skaber omsætning, arbejdspladser og beskæftigelse.

Jeg mener derfor ikke, at de fire E'er kan sidestilles som rationaler. Economic Impact er instrumentelt $i$ den forstand, at økonomisk vækst bliver målet, og kulturen bliver et middel. Mål og midler bliver byttet om, og det kan have nogle uheldige virkningen $\mathrm{fx}$ i forhold til, hvad det er for kulturaktiviteter, der får offentlig støtte. Kunsten og kulturen bør være målet, mens økonomien er midlet. Kulturen har værdi ud over den markedsmæssige værdi, og disse non-market værdier knytter sig til rationalerne om Enlightenment og Empowerment, som derfor bør være de væsentligste rationaler i den offentlige kulturpolitik.

Ofte sættes kulturens instrumentalisering op som en modsætning i forhold til "kulturens egenværdi". Kulturen har en værdi i sig selv, uanset om nogen værdsætter denne værdi. Det kan være tilfældet for noget kunst, men det gælder ikke for den brede kulturpolitik, hvor udgangspunktet for kulturpolitikken må være den værdi kulturen har for borgerne - her også non-market værdier, der ikke alene kommer brugerne, men også ikke-brugerne til gode.

Det er interessant, at et meget stort forskningsprojekt i UK "The Cultural Value Project: Understanding the value of arts \& culture" (Crossick og Kaszynska, 2015), finansieret af Arts \& Humanities Research Council, netop er kommet til samme konklusion. Forskerne havde sat sig for at besvare to grundlæggende spørgsmål: 1) At identificere de forskellige komponenter, der tilsammen udgør kulturens værdi, og 2) At overveje og udvikle metoder, der kan bruges til at evaluere disse komponenter. De konkluderede, at det enkelte menneskes oplevelser må tages som det primære udgangspunkt, når kunstens og kulturens betydning skal vurderes, og meget forsimplet identificerede de bl.a. tre væsentlige områder: 1) danne reflekterede individer, der forstår sig selv og andre, 2) danne engagerede borgere, og 3 ) styrke fantasi og kreativitet, og dermed innovation. I Dortes 
terminologi svarer det til rationalerne Enlightenment og Empowerment.

Tusind tak for dine mange inspirerende bidrag til den kulturpolitiske forskning, Dorte.

\section{Referencer}

Belfiore, E (2002). Art as a means towards alleviating social exclusion: Does it really work? A critique of instrumental cultural policies and social impact studies in the UK, International Journal of Cultural Policy, vol. 8., no.1, pp 91-106.

Bille Hansen, T (1997). The Willingness-to-Pay for the Royal Theatre in Copenhagen as a Public Good, Journal of Cultural Economics, vol. 21., no. 1, pp 1-28.

Bille, T (2012). The Scandinavian approach to the Experience Economy - does it make sense?, International Journal of Cultural Policy, vol. 18, no. 1, pp 93-110.

Bille, T \& De Paoli, D (2012). Approaches to stimulate and support the cultural entrepreneur - the case of Denmark and Norway, I: Giep Haggort (ed.): The Entrepreneurial Principles of the Cultural and Creative Industries, pp 81-83.
CKO, Center for Kultur- og Oplevelsesøkonomi (2011): Behovsanalyse. Kreative erhverv i Danmark, København.

Crossick, G \& Kaszynska, P (2015). Understanding the value of arts and culture, The AHRC Cultural Value Project, Arts \& Humanities Research Council, UK.

Duelund, P (ed.) (2003). The Nordic Cultural Model, Nordisk Kultur Institut, København.

Jensen, J (2003). Expressive Logic: A New Premise in Arts Advocacy, The Jorunal of Arts Management, Law and Society, vol. 33, no. 1, pp 65-80.

Mathiasen, SB et al. (2006). Rammebetingelser for Københavns kreative brancher, Imagine...Copenhagen Business School, København.

Skot-Hansen, D (2005). Why Urban Cultural Policy? I: Jill Robinson (ed.): Eurocult21, Integrated Report, Eurocult21, Helsinki, pp 31-39.

Vestheim, G (2004). Instrumental Cultural Policy in Scandinavian countries - a critical historical perspective, European Journal of Cultural Policy, vol. 1, no. 1 , pp 57-71. 